\title{
Theoretical Models of Integration of Interactive Learning Technologies into Teaching: A Systematic Literature Review
}

\author{
Laila Mohebi \\ Zayed University, Dubai, United Arab Emirates \\ https://orcid.org/0000-0003-2640-4532
}

\begin{abstract}
With the fast progress of technology and the vast amount of research papers related to technology integration in education being published yearly, a study that reviews models used in these papers is needed. Therefore, this paper (1) reviewed and analysed theoretical frameworks with models used for integration of technology in classrooms, (2) reviewed studies that discussed the impact of technology integration on students' learning capabilities, and (3) discussed the importance of preparing teachers to effectively integrate technology in teaching. The models reviewed were: Teacher Thoughts and Action Process (TTAP), Theory of Planned Behavior, Expectancy-Value Theory of Achievement Motivation (EVAM), Substitution Augmentation Modification Redefinition (SAMR), Technology Acceptance (TAM), Unified Theory of Acceptance and Use of Technology (UTAUT), and Technological Pedagogical and Content Knowledge (TPACK).
\end{abstract}

Keywords: technology integration; technology models; technology in classrooms; technological pedagogical; content knowledge

\section{Introduction}

Technology has become an inseparable part of our daily lives, and therefore it warrants its usage in training teachers in order to enhance learning and teaching in the 21st century. Today, updating software and educational materials have been made easier through the use of technology. Students and teachers can be connected worldwide through Internet-enabled devices and learners, therefore, can communicate across the globe and share vital information and the experience of learning. Several studies provided evidence that technology is essential in modern learning environments and that technology being readily available in many countries (; Pavlou, 2019), yet its application in education is still ineffective. Different theories and models have been developed to assist teaching and learning using different forms of technology to support the challenging integration of technology in education. In their analysis of e-learning 
theories and models, some authors (Cheng et al., 2020; Avci et al., 2020) suggested that in order to successfully adopt technology, it is essential to understand how to facilitate technology integration in educational settings and the importance of this. They further define theories as "an empirically-based explanation of factors that affects learning when integrating technology with education" (Sang et al., 2010, p. 109).

In the last few decades, various models and theories have been used to study technology integration in classrooms and teachers' roles, preparedness and capabilities. Ideally, theories and models are sources that support educators in the integration process. Studies have shown many learning theories, but the dominant categories are cognitivism, behaviourism, and constructivism (Mahini et al., 2012). With the fast progress of technology and the vast amount of research papers about technology integration being published yearly, a study that reviews models and analyses is needed. In addition, a thorough review of theoretical frameworks used the integration of technology in classrooms is scarce. Therefore, this paper has the following research objective:

1- To review and analyse theoretical frameworks with models used for integration of technology in classrooms;

2- To review and understand the impact of technology integration on students learning capabilities; and

3- To review the importance of preparing teachers to effectively integrate technology in teaching.

\section{Theoretical Framework}

The below sections will review and analyse the following models:

1- $\quad$ Teacher Thoughts and Action Process (TTAP).

2- $\quad$ Theory of Planned Behaviour.

3- $\quad$ Expectancy-Value Theory of Achievement Motivation (EVTAM).

4- $\quad$ Substitution Augmentation Modification Redefinition (SAMR).

5- $\quad$ Technology Acceptance Model (TAM).

6- $\quad$ Unified Theory of Acceptance and Use of Technology (UTAUT).

7- $\quad$ Technological Pedagogical and Content Knowledge (TPACK).

These models were selected because they are widely used by researchers when reviewing papers that focus on integrating technology in classrooms. The frameworks complement each other and can investigate different elements of technology integration into the educational context. For instance, to examine influencing factors of ICT integration in China, Sang et al. (2010) used the Teacher Thoughts and Action Process model (TTAP), the Theory of Planned Behaviour (TPB), and the Expectancy-Value Theory of Achievement Motivation (EVAM). What follows will focus on each model and the researchers that chose it as their framework.

\subsection{Teacher Thoughts and Action Process (TTAP) Model}

The Teacher Thoughts and Action Process (TTAP) model explains the common relationship between teacher thought processes and related teacher behaviour. The model was developed by Peterson and Clark in 1978. They presented and 
advocated the teaching profession and the role of teachers as important and as specialized as that of a doctor, lawyer or any other professional. While their research aimed to understand the overall dynamics of a classroom and the quality of education imparted, they maintained that it is imperative to understand the thinking and the mindset of a teacher which is at the base of planning, decision-making and the demonstration of certain interactive behaviours within a class and with the students. Therefore, the overall objective of TTAP is to dig deeper into understanding the fundamentals and underlying intricacies of the teaching process, and how it is closely associated with the thought process of the teachers and observable actions that take place as a result of that. In general, the model consists of two aspects:

- Teacher's thought process: an individual thought process is a phenomenon which takes place inside the brain and cannot be measured directly. It can only be measured based on the actions taken as a consequence and their overall impact. The thought process includes the engaging thoughts and decisionmaking, the belief system and the associated theories built around it, and finally, the overall planning part which can include the three stages of pre-, post- and interactive thoughts. It can also be used to categorize teachers according to these three stages as teachers distinguish themselves in their thought processes.

- Teacher's actions and their effects are observable and can be easily demonstrated, measured and assessed while the teacher is engaged in a classroom activity. The parameters that can determine the teacher's measurable actions would include the engagement and overall behaviour of the teacher as well as the students and e students' overall achievements.

The core of the model is that interactions between the underlying factors in both streams (i.e., the thought process and the observable actions) are cyclic and not linear. Whereas, teacher's thought process cannot be directly measured; it can however be influenced by a number of factors that limit or inhibit it in a certain direction, either for the best or for the worse. For instance, the autonomy given to the teacher in designing a curriculum as well as the involvement and participation in the overall decision-making process would determine the flexibility and level of effort put in place by the teacher in his/her thought process. Similarly, the student-teacher and teacher-student interaction is reciprocal and closely associated with the overall achievement of the students.

\subsection{Theory of Planned Behaviour}

The Theory of Planned Behaviour (TPB) by Ajzen (1980) is an extended work towards the earlier known model which is the Theory of Reasoned Action (TRA). In this regard, Ajzen stated that:

human behaviour is guided by three kinds of considerations: beliefs about the likely consequences of the behaviour (behavioural beliefs), beliefs about the normative expectations of others (normative beliefs), and beliefs about the presence of factors that may facilitate or impede performance of the behaviour (control beliefs) (Ajzen $\mathcal{E}$ Fishbein, 1980, p. 2). 
This model argues that a particular action by a person is driven by the attitude towards that particular behaviour. In general, the TPB advocates that there are certain parameters and factors which all come to contribute to a person's intent towards a particular behaviour. The overall intent of a person is believed to be driven by the following three factors:

- Attitude to Use (ATU): the attitude towards certain behaviour;

- Subjective Norm (SN): the suitability and importance of exhibiting certain behaviour as perceived on behalf of the people significant in certain scenario;

- The perceived behavioural control (PBC): the overall controlling factor and the pre-conceived level of difficulty or ease in exhibiting a certain behaviour. PBC is said to have a major impact in making strong correlations with one's intent to use technology.

Once an insight is created in a person's positive or negative intent towards certain behaviour, the behaviour can easily be understood. In this case, the TPB concept has been effectively used to evaluate the intention for adoption of technology in pre-service as well as in-service teachers.

\subsection{Expectancy-Value Theory of Achievement Motivation}

The Expectancy-Value Theory of Achievement Motivation (EVTAM) is a model developed by Wigfield and Eccles (2000). This model was originally proposed to measure children's keenness in performing, achieving and carrying on a certain task. The EVTAM is primarily used "to explain how expectancies and values directly and indirectly influence achievement, choices, performance, effort, and persistence across a wide range of academic and physical domains and age groups" (Hood et al., 2012, p. 73).

The three main factors of the expectancy-value theory framework are presented as follows:

- Expectation of Success: the expectations of an individual about the completion of a task or the adoption of a technology both in the present as well as in future scenarios;

- Achievement Related Choices: the overall goals and objectives of an individual in achieving and completing certain tasks;

- Associated Task Value: the value proposition from an individual committed to the task. This includes the importance of the task, its overall usefulness, the value to oneself, and the cost of completing.

In real-life scenarios, every individual has a different belief system, exhibits different attributes and acts differently to changes or new requirements. Some individuals would be quick learners and would adapt very easily to the change in their environment, whereas others would not. Overall performance of an individual is a direct derivative of the overall belief system, expectations and the value associated with that task. . Additionally, it allows researchers and policy makers to work effectively on the areas which directly impact the overall performance. Applying this model in a classroom environment provides a very useful insight in the end results. To make it clearer, any combination of beliefs and evaluations developed about a certain classroom management technique 
could be either positive or negative. If positive, the teacher would likely continue to use it, but if negative, he/she would avoid it.

\subsection{Substitution Augmentation Modification Redefinition (SAMR) Model}

The Substitution Augmentation Modification Redefinition (SAMR) model, developed in 2010 by the education researcher Ruben Puentedura (Terada, 2020), is an important guideline and a fundamental framework for the integration of technology in today's classrooms. In today's fast pacing and technologically evolving the world, every student is a carrier of a technological intervention which is a substitute and an augmented aid to conventional means of teaching. SAMR discusses the use and integration of these technological interventions/devices such as smart phones, iPads, Kindle, smart tabs, etc. into the conventional means of teaching so that both of these streams can be clubbed together to enhance the effectiveness of the teaching methods. According to Chou et al. (2012), SAMR is a method for both staff and students to gain expertise in new consumer technologies and software in order to enhance 21st century skills. SAMR views each technological intervention/device as a new task and offers a structural model which defines the stages of these transitions. Broadly segregated into 'Enhancing' and 'Transforming' SAMR within these two broad categories have the following four stages:

- Substitution: specifies the incorporation of technology into the conventional classroom system whereby the technology (digital) acts as a better substitute for the already existing teaching methods (analogue) and practices. This is the realization part of the framework. Students, for example, can utilize a voice thread software to build a presentation that allows viewers to remark and annotate.

- Augmentation: centres around the technology modalities which is to be used as a direct or indirect tool for assisting and aiding the entire education process. It is seen as a functional improvement. Students, for example, can utilize Google Doc's comment function to engage with others, or Google Earth to "visualize" geography and tag specific spots.

- Modification: requires the modification in the existing processes and practices to make room for the technology to play its new role. Tasks are redesigned according to the technology used. For example, students can use audio-books to add audio to stories.

- Re-definition: allows teachers to create new avenues, new streams and new tasks keeping in view the offerings technology has to make that could not have been imagined before. For example, instead of paper and pencil, pupils can choose a word processing tool.

At the first two levels, technology is used for the enhancement of the learning experience, whereas in the last two levels, the technology is used to transform learning tasks and experiences through modification and redefinition. Thus, the use of technology can better promote student outcomes. In this sense, Angelo's study (2017) explored teachers' and administrators' perception of the SAMR model in integrating technology into the classroom environment. The study found that educators using the SAMR model were more capable of facilitating technology adoption at the service of better pedagogical results. Also, it 
underscored that SAMR altered teachers' observable practices by pushing them to incorporate technology on a greater degree.

\subsection{Technology Acceptance Model (TAM)}

The Technology Acceptance Model (TAM) is a working model developed by Davis (1989) and is an extension of the originally known Theory of Reasoned Action (TRA) (Ajzen \& Fishbein, 1980). TAM discusses the behavioural assessment of the entities which are the end-user or adopters of the use and adaptation of technology. In education, teachers are the integral part of the equation which would pave the way for technology adoption. The original TAM is influenced primarily by two basic factors from a user's point of view. The enhanced Technology Acceptance Model (TAM) suggests that perceived usability and perceived usefulness are direct drivers of technological acceptance behaviours. As Gong et al. (2004) stated "Perceived usefulness is defined as the prospective user's subjective probability that using a specific application system would increase his or her job performance within an organizational context" (p. 366). Perceived ease of use, on the other hand, refers to "the degree to which the prospective user expects the target system to be free of effort" (Gong et al., 2004, p. 366).

- Individual's Perceived Usefulness: the mindset and the benefit that one thinks would get from adopting and using a certain technology;

- Individual's Perceived Ease of Use: is the overall keenness of an individual driven by the motivation that the work would be facilitated and simplified by adopting a certain technology.

There are, however, many intrinsic and extrinsic factors that might exert an influence on an individual in exhibiting these elements. These factors can be cultural barriers, linguistics, social factors, and the political framework of a country or an organization. There have been many changes to the original TAM and researchers have added a number of other interrelated factors to this model. TAM2 is an extended mode of the original work which also takes into account parameters like voluntariness of a user, social image, social influence and perceived importance and relevance of the technology to one's tasks, output quality, and end results. Various studies used the Enhanced Technology Acceptance Model (ETAM) as their theoretical background for explaining technology use and adoption (Goh \& Wen, 2020; Vanduhe et al., 2020; Sukendro et al., 2020). These studies have found confirmation that perceived usefulness affects attitudes and degree of approval of a specific technologically-enabled practice.

\subsection{Unified Theory of Acceptance and Use of Technology}

The Unified Theory of Acceptance and Use of Technology (UTAUT) is created by Venkatesh et al. (2003) to understand the acceptance process. They integrated eight previously used models in the field of technology acceptance research into a single model based on conceptual and empirical commonalities between them. These eight models are: the Theory of Reasoned Action (TRA), Technology Acceptance Model (TAM), the Theory of Planned Behavior (TPB), the Motivational Model (MM), the combined TAM and TPB (C-TAM-TPB), the 
Model of PC Utilization (MPCU), the Diffusions of Innovations Theory (DOI) and the Social Cognitive Theory (SCT). The UTAUT model contains five direct dimensions of behavioural intention and use:

- Performance expectancy: "the degree to which an individual believes that using the system will help him or her to attain gains in job performance" (Venkatesh et al., 2003, p. 447);

- Effort expectancy: "the degree of ease associated with the use of the system" (Venkatesh et al., 2003, p. 450);

- Social influence: "the degree to which an individual perceives that important others believe he or she should use the new system" (Venkatesh et al., 2003, p. 451);

- Facilitating conditions: "the degree to which an individual believes that an organizational and technical infrastructure exists to support the use of the system" (Venkatesh et al., 2003, p. 453);

- Behavioural intention: the person's intention to use a certain technology system.

The UTAUT model also explains how moderating factors can influence the five dimensions and cause individual differences in technology usage. Gender, age, experience, and voluntariness of usage are the four moderating factors. By combining and improving upon existing information and communication technology (ICT) acceptance models, it is argued that the UTAUT model should now serve as a standard for the technology acceptance literature. It is worth mentioning that Venkatesh, Morris, Davis, and Davis (2003) developed UTAUT in 2003 and progressed it into UTAUT2 in 2012 by incorporating three new constructs , such as hedonic motivation, price value, and habit (Tamilmani et al., 2021).

\subsection{Technological Pedagogical and Content Knowledge (TPACK)}

The TPACK framework builds on the work of Shulman (1986), who was the first to shed light on the pedagogical content knowledge (PCK) concept. He paid attention to the problem regarding the requirement of a more cohesive theoretical framework with is in respect to teachers' knowledge, as well as what they are able to undertake. To provide a comprehensive explanation of the relationship between content knowledge and pedagogical knowledge, Shulman (2013) came up with the concept of PCK. He envisioned PCK as crossing the boundaries of the ordinary knowledge on subject content to inculcate ideas on how to approach and deal with special subject matter. Teachers need to go beyond mere possession of content or subject knowledge. It is equally essential that teachers should have the requisite skills to teach that particular knowledge in a manner which is easily comprehensible for the students. Hence, it is the expression of the subject in such a manner that facilitates its understanding to other individuals.

Shulman (1986) first presented the concept of pedagogical content knowledge (PCK) in his book "Those Who Understand: Knowledge Growth in Teaching". Through this concept, he emphasized the importance of finding the method of demonstrating and conveying the subject that makes it comprehensible to others 
(content). He also outlined the need to equip teachers with knowledge delivery strategies (pedagogy). Shulman (1986) described how teachers' understanding of educational technologies interacts with pedagogical content knowledge to produce effective teaching through technology. In addition, Shulman (1986) presented that the understanding of what causes a particular subject to be either simple or complex to learn is in fact a part of PCK. In the pursuit of effective teaching of a subject, the teacher should be thoroughly aware of the difficult areas where students (or student teachers) often struggle with. These areas can vary depending upon the notions which the students possess along with their respective ages and backgrounds. Students may get inaccurate information and develop misunderstandings about the topic area if there is no broad basis of content knowledge. If the students' conceptions are based on false information, teachers should possess a set of strategies which could potentially be successful in identifying the wrong learning patterns.

As a progression of the pedagogical content knowledge (PCK) framework initiated by Shulman in 1986, Mishra and Koehler (2006) conceptualized the TPACK framework. Shulman (as cited in Young et al., 2013) defined PCK as a teacher's ability to transform subject-matter knowledge into accessible forms that all learners could master. However, Mishra and Koehler (2006) added that it also means that knowing and understanding how ICT may be used to obtain and process information can support learning in combination with PCK. TPACK can be said to be a natural extension of the PCK concept as it incorporates the technological aspect. Hence, TPACK not only stimulates the use of technology in education, but also provides understanding to the teachers about the integration and interaction of technology with pedagogy and content knowledge (Tondeur et al., 2016). The TPACK framework can be visualized by three overlapping circles, with each circle representing an element of teachers' professional knowledge. This framework resulted in seven aspects of teachers' professional knowledge with TPACK positioned at the linking core of these circles. These different forms of knowledge are the context in which teachers obtain and transmit their knowledge.

- Content Knowledge

The content knowledge is the teacher's knowledge about the actual subject matter to be learned or taught. For every subject taught in school-such as science or history-other content knowledge is critical for teachers. As a result, teachers must comprehend the principles of the fields in which they teach. Knowledge of concepts, theories, ideas, organizational frameworks, evidence and proof, as well as established procedures and techniques to producing such knowledge, are examples that constitute content knowledge.

- Pedagogical Knowledge

Pedagogical knowledge is described as the profound understanding of the processes and strategies of teaching and learning. This type of knowledge pertains to understanding how students learn, general classroom management abilities, lesson preparation, student evaluations, classroom procedures or methods, the nature of the intended audience, and methodologies for assessing 
students' comprehension. Cognitive, social and developmental theories can support the teacher when designing and shaping teaching in the classroom. A teacher with deep pedagogical knowledge knows how to stimulate student learning in the form of constructing knowledge and acquiring skills (Koehler \& Mishra, 2009).

- Pedagogical Content Knowledge

Shulman (1986) described pedagogical content knowledge as the knowledge of pedagogy that is applicable to teaching specific content. A teacher with deep pedagogical content knowledge is able to select the appropriate teaching methods and instructional materials that fit the content.

- Technology Knowledge

Koehler and Mishra (2009) described how technology knowledge is always a difficult domain, because with the fast pace of technological developments, any definition of technology knowledge is in danger of becoming outdated. They used the definition of 'Fluency of Information Technology (FITness)' as described by the National Research Council (NRC). For information processing, communication, and problem solving, FITness necessitates a deeper grasp and command of information technology than the standard notion of computer literacy. A teacher with a strong understanding of technology is able to do a wide range of activities utilizing information technology and to devise novel approaches to completing a particular work.

- Technological Content Knowledge

Technological Content Knowledge (TCK) is the knowledge about how technology and content are related and influence each other. Consequently, teachers not only need to have a deep knowledge about a subject matter, but also should have the insight about how a subject matter can be changed when certain technologies are applied. Also, they need to know which particular type of technology is best suited for addressing subject-matter learning.

-Technological Pedagogical Knowledge

Technological pedagogical knowledge is defined as the knowledge about the existence, components and capabilities of various technologies in teaching and learning settings (Mishra \&Koeler, 2006). If a teacher is familiar with up-to-date technologies, he/she can make an informed choice about which particular technology fits best with the purpose of a learning activity, thereby creating and maintaining an effective, high-quality learning environment.

-Technological Pedagogical Content Knowledge

Mishra and Koehler (2006) described Technological Pedagogical Content Knowledge (TPCK) as "an emergent form of knowledge that goes beyond all three components (content, pedagogy, and technology)" (p. 1028). They further added that:

TPACK is the basis of effective teaching with technology, requiring an understanding of the representation of concepts using technologies; pedagogical techniques that use technologies in constructive ways to teach content; knowledge of what makes 
concepts difficult or easy to learn and how technology can help redress some of the problems that students face; knowledge of students' prior knowledge and theories of epistemology; and knowledge of how technologies can be used to build on existing knowledge to develop new epistemologies or strengthen old ones (Koehler E Mishra, 2009, p. 66).

As a result, it reflects a type of knowledge that is essential to instructors' work with technology. Quality teaching requires a deep understanding of the relationship between these three concepts and how to make the best use of these three concepts. Insight and deep knowledge is needed to create the best possible learning environment in each unique situation, because there is no technology solution or a method that works for every instructor. Hence, TPACK could be fine-tuned, broadened and developed upon to consider numerous variables which impact-either positively or negatively-on the quality and frequency of technology usage in the field of education (Koh et al., 2015).

For instance, TPACK was used as a framework to audit the capabilities of finalyear teacher education students in Australia and to review teacher education programs in regard to their student preparation in TPACK capabilities. Similarly, TPACK can be used to implement an instructional design model in a technology integration course and help teachers, trainers, policymakers, and other educators who are directly or indirectly responsible for the professional development of teachers.

Tondeur et al. (2012) investigated how Teacher Education Institutes (TEI) prepare pre-service teachers for integrating information and communication technology (ICT) in their classroom practice. Their findings showed that the participating institutes were shifting away from ICT as a "stand-alone" subject towards incorporating ICT throughout the curriculum. Furthermore, the institutions sponsored initiatives to improving pre-service teachers' TPACK. They claimed that improving teachers' TPACK abilities should be viewed as part of the overall policy development of teacher education institutes with an emphasis on curriculum redesigning, vision building, ICT-planning, leadership, and collaboration within and between institutions and training personnel.

Harris and Hofer (2014) argued that regardless of the different understandings of TPACK's seven areas among college educators, professional development individuals need to understand how to operationalize the model in teacher training efforts on district level in North America. The researchers held a symposium where educators participated and narrated their experience in using TPACK in professional development workshops. Their findings indicated that universities operationalizing of TPACK was different from the in-service educators who lacked efficacy in doing so.

The study of Hao and Lee (2016) aimed at understanding pre-service teachers concerns related to flipped classrooms' technology integration. The results indicated that the pre-service teachers' main concerns were related to technology knowledge. Based on these results, they recommended updating curriculums and instructions in higher education institutes in a manner where pre-service 
teachers get equipped with fundamental knowledge and skills to teach in 21st century classrooms.

Moreover, TPACK is widely proposed as the body of knowledge that teachers should acquire for them to have proper capabilities of constructively integrate technology in their teaching. Teachers with TPACK capabilities can use instructions that assist their students to quickly understand and use technology in their learning. In a study by Harris and Hofer (2014) on different views regarding the use of TPACK, participants reported that the model helped them learn from their past experiences. Teachers with TPACK capabilities can use the different experience to assist students' learning. In this respect, as Sang et al. (2010) argued, teachers who are TPACK competent are aware that technology cannot replace content or pedagogical knowledge, but they see technology as an added dimension.

Another study investigated how an online learning environment might affect the participants and technology integration capabilities in a certain course (Ellis et al., 2016). The participants who were pre-service teachers created lessons to be used in an online learning environment and the results showed that the online learning environment had supported the development of abilities to link content with technology and to choose the proper technology that could contribute constructively during the learning process.

A study that complements Ellis et al.'s research (2016) was conducted by Yeh et al. (2017). This study asserted that teachers can select the appropriate technology and implement it in the classroom based on their TPACK, particularly when it comes to in-service teachers whose TPACK is built and consolidated by trialand-error throughout the years of teaching. By using video and disciplinefocused questionnaires to measure TPACK, they concluded that:

in-service teachers' TPACK can be very different from that which preservice teachers develop, because teaching experiences and beliefs can personally vary and interact. Teachers' knowledge should first be developed for practice and then in practice, and ultimately become of the teachers (Yeh et al., 2017, p. 61).

Further, it is worth mentioning that literature (Miguel-Revilla et al., 2020; Castéra et al., 2020; Tondeur et al., 2019) indicated that TPACK model has been used extensively in research and teacher training, however it doesn't indicate how teachers can acquire a better grasp of the interaction between content, pedagogy, and technology. Most researchers see that teachers can unlock this understanding by acquiring basic competences in hardware and software programs. This argument cannot be established without proper teacher training that requires TPACK, therefore, more studies are needed.

\section{Implications}

There are numerous implications that need to be highlighted. The following sections will address ICT in education, impact of technology in the classroom, implications for students, implications for teachers such as factors that influence teachers' willingness and abilities to integrate technology and required 
knowledge and skills for teachers, as well as the importance of teaching the instructors.

\subsection{ICT in Education}

ICT, in general, refers to technology that provides access to information via telecommunications. ICT is an abbreviation for Information and Communication Technologies, and it refers to a broad range of technical tools and resources used to communicate, distribute, generate, store, exchange, and manage data. Some of the components of ICT include wireless networks, the internet, cell phones, and other communication media. The application of ICT is making changes in economic and social development worldwide (United Nations, 2017). Certainly, technology has significantly improved teaching and learning and is expected to impact education in many ways. Learners of today grow up with numerous technological tools, and therefore, the way of teaching is being adjusted to the possibilities of the new modern technologies. In order to cater to the needs of 'digital natives', it is relevant to pay attention to the medium used. As discussed earlier, technology integration has reinforced the learning surroundings and classroom guidelines by allowing learners to complete their assignments using internet-enabled devices.

The school curriculum entails the infusion of technology to heighten learning in multi-disciplinary settings. Technology integration equips the learners with a sense of power and allows for more improved learning in broad topics. Concordant with the extant literature, the study, design, development, application, implementation, and administration of computer-based information systems is referred to as Information and Communication Technology (ICT).It encompasses all types of computer and communications equipment and software used to produce, design, store, transmit, interpret, and modify data in various formats (Chandler \& Munday, 2012). In education, personal computers, laptops, tablets, and mobile phones are commonly used tools.

Because of the above, several types of technologies have been identified to facilitate learning. These technologies include the use of computers in the classroom, creating class websites and blogs, and the use of digital microphones in class, mobile devices, smart interactive whiteboards and online media. This section discusses two tools: the use of computers in classroom and creating class websites and blogs. In the modern society of the 21st century, it is not strange to see at least one computer in every classroom. A classroom computer is any electronic device that allows students to connect to the internet to study, create, and accomplish assignments and schoolwork. As such, a laptop or tablet can also be considered as a computer. Teachers can use these computers to assign work to students and create study groups in a classroom. They can also use computers to illustrate visually-related subjects, which help students learn easily and gain more insight. Thus, applications can be installed on modern computers which help students learn better than the conventional way. For instance, students are in a position to use windows explorer to learn complicated concepts. The Encarta was one of the earliest applications used by students as a learning aid. 
Using computers in class comes with a number of benefits. For instance, computers provide engaging activities, which make learning more interesting and profound, and enable the development of a broader range of personalised and varied instruction plans. Doubtless, before the emergence of computers-and due to time restrictions- it was difficult to provide students equal opportunities and therefore they were struggling with all the help they needed for a particular subject because the class had to move forward. The use of computers has enabled the division of work and attention amongst students (Stockwell \& Liu, 2015). On the other side, computers have their disadvantages. Firstly, students have to be taught how to use computers before they can start learning with them. This can take time away from the traditional subjects to ensure the students are competent with these gadgets. Also, these gadgets come with a significant amount of potential distraction to the students. For example, students can log into social media sites like Facebook and YouTube without teachers' knowledge.

The second tool is the use of websites and blog posts. Today, it is very easy to create a website or blog platform. On this platform, teachers can post assignments or even start a debate on a certain topic. The ability to create these websites gave birth to the concept of e-learning. E-learning refers to the use of electronic technology to access educational content outside of the traditional classroom setting. Correspondingly, most of the colleges in the United States and Europe have their e-learning portals where students can learn from the comfort of their homes or workplaces. What is important to note is that although many people still adhere to traditional universities, online learning using these websites proves to be an attractive alternative, as it can be attributed to the fact that students can study in their own time and with reduced or no costs. As a result, it is presented as a great way to study many different fields and is regarded as pivotal in boosting self-motivation and self-improvement. Secondly, it is also effective because students can finish homework quickly and a lot of time is spared, which can be used to work or play.

Finally, it is particularly noticeable that e-learning websites enable students with an internet connection to learn from any place and on a wide variety of subjects. However, the use of this system is accompanied by a few disadvantages. Firstly, online learning does not offer human interaction, so some participants of online education may not learn other life skills such as patience, getting rid of disappointments, and how to compete. Also, in some cases, online learning cannot fully cope with the large number of students looking to join the discussion on the websites. Last but not least, using websites or blog platforms can also be difficult for disciplines that involve hands-on practice, such as engineering.

\subsection{Impact of Technology in the Classroom}

While media are the vehicle to deliver instruction, any benefit comes from the instructional method itself. Hence, it should be borne in mind that digital devices have different features that produce a unique experience for learners. 
Some observers argue that technologies are incompatible teaching requirements and that it is difficult for teachers to incorporate computers into regular classroom instructional practices. However, in the last few years, the positive impact of integrating technology in the educational context became undeniable. Different studies (Johnston et al., 2019; Woo, Dondanville et al., 2020) have proved the importance of technology in the learning environment. For instance, evidence supports the finding that ICT can serve different purposes if used effectively. It can provide a platform for professional development for both preservice and in-service teachers. It can also aid in teaching and learning processes and increase teacher knowledge and skills.

Similarly, it can improve educational management systems, and the steadiness and quality of instruction both for formal and non-formal education, and increase prospects for more student-centered pedagogical methods. Likewise, since ICT can overcome gender disparity and language and disability obstacles, it can broaden sources of information and knowledge, nurture collaboration, promote creativity, and strengthen higher-order thinking skills. Finally, it can provide flexibility of delivery and reach learners outside the traditional educational systems. Because education is paramount for development, ICTenabled interactive learning is considered a way to support change, improve students' skills, and prepare for a global economy and the current knowledgebased society. Further, it is well known that the way that technology is used in education improves the quality of teaching and learning more than the technology itself. Hence, ICT can play an influential role in studying, communication and flexibility. Modern technology requires the work force to become life-long learners, and the effective use of ICT can maintain that.

\subsubsection{Implications for Students}

The use of technology in teaching can have a profound effect on students' learning. Brown (2017) highlighted this positive impact of technology when he stated that with access to technology, students can engage in tasks which demand higher cognitive inputs than was required in original versions of the task. This implies the development of higher cognitive capabilities among students when they use technology appropriately. He found higher levels of reasoning and vocabulary in students who used educational media both with and without teacher mediation. Numerous research papers (Harrison et al., 2002; Tamim et al., 2011; Hardman, 2019) demonstrated that ICT increases students' achievements and supports their learning and attainment. For instance, a second-order meta-analysis in a recent study was used to synthesize diverse research findings from 25 meta-analyses addressing technology integration and its impact on students' achievement. The review synthesized data from 1,055 primary studies and summarized 40 years of research into the effect of computer technology on students' achievements. The findings showed that students in technology integration classrooms perform $12 \%$ higher than students in the traditional settings.

There is evidence from 17 impact studies and surveys carried out at the national and international levels that the technologies used in the classroom positively 
impact students' learning. Thus, ICT improves students' attainment and increases their performance in mathematics and other disciplines. In a study that involved 6th and 8th graders in investigating the impact of technology on students' performance in mathematics, students who were provided with videoclip instruction improved their math achievement compared to students who received traditional classroom instructions without technologies. Additionally, studies have shown that technology can impact language acquisition, enhance literacy development, support learning, enhance self-esteem, and motivate students. Indeed, studies showed that technology provides many opportunities for students to improve their literacy. Notably, several studies indicated that learning in a multimedia environment helps students gain better language skills than students using a traditional environment, as technology can be used to improve language development by enhancing efficiency of access, authenticity, and comprehensibility. In addition, research evidence indicated that technology can be used to improve quantitative assessment performance in several subjects. If students are introduced to computers at early stages of learning, they will be motivated to learn and have better learning outcomes than those who are not introduced to computers.

\subsubsection{Implications for Teachers}

The positive effect of interactive learning technologies is not limited to students, but it also benefits teachers. Because of a more collaborative approach among instructors, ICT improves efficiency in work planning and preparation. Interestingly, scholars stress that the maximum positive impact is found when teachers are experienced users and have a certain level of mastery in ICT integration in their teaching. Although in surveys, some teachers were strictly on the view that ICT cannot replace the teacher, it is clear that the addition of ICT has provided a new facet to effective teaching. Creating an interactive forum to the quicker distribution of knowledge can overcome distance challenges and allow a more agile learning process. Thus, this exemplifies how ICT can propel academics towards a newer horizon. Statements regarding the appropriate use of ICT shed light on several managerial advantages. These include the ability to use a dual shift system (day/evening) within the university, multi-grade schools, a more dynamic scheduling, and better transparency regarding policy development right from admission until graduation. Several other advantages include increased capabilities of learning due to the wealth of information, efficacious teaching through ICT tools and breaking down geographical challenges through virtual classrooms. In addition, it provides a wider approach to students who are challenged with the use of assistive technologies and assistance of radio and satellite to expand beyond geographical masses and increased speeds of communication.

\subsection{Factors that Influence Teachers' Willingness and Abilities to Integrate Technology}

There are many obstacles to technology integration in the classroom, such as scarcity of funds, hardware and software. However, the main obstacles are teachers' weak capabilities. It is well proven that teachers' skills and attitudes determine the success of technology integration. Through research and observation, eight main areas of consideration were important for teachers to 
integrate technology. These areas were: 1) fear of change; 2) training in basics; 3) personal use; 4) teaching models; 5) learning base; 6) climate; 7) motivation; and 8) support. Thus, if higher education institutes contribute in enhancing some of these areas before student graduates, it would ease the pressure on schools once the pre-service teachers become in-service teachers. Thereby, enhancing the chance of successful technology integration in schools is required.

Additionally, it can be pointed out that there are several disadvantages concerning the use of ICT in the field of education. Several of such disadvantages are: increased demand for monetary resources, frequent critical training of the staff for the correct use of such material, and increased risk of distraction of students due to the availability of chat forums and PC games which requires constant supervision that adversely hinders the quality of teaching provided. Also, accidental entry into illegal sites containing unsuitable material, and strain on the teacher-student bond as opposed to the more traditional talk-and-chalk method. The most significant constraints are the discipline and attention of the student's personal views of the teacher within the class preparation for such.

Among the environmental factors, teachers mentioned barriers, such as issues related to computer facilities, available support, management of resources and human resources provided by the school, and varied educational disciplines are allotted different amounts of time to use the computer lab. Moreover, opportunities for in-service training provided by the school influenced their initiatives of using technology in the classroom. Personal characteristics, such as instructors' opinions about teaching, their experience with technology, and their willingness to try new things were found to be affecting their willingness to integrate technology.

The most frequently mentioned social factors were having colleagues to work with as a team, an open atmosphere within a school society, and reactions from students, parents and the community. The attitudes of school management were also a critical factor. The teachers were concerned about the fact that low-income families might not have the financial resources to provide their children with the necessary technological tools. Finally, curricular factors were issues related to the goals and instructional settings within particular courses and the level of control about the use of technology. Also, teachers showed concern for integrating new strategies with existing strategies. Some teachers needed more time and effort to learn new skills and prepare new activities using ICT. Similarly, other researchers attempted to comprehend how pre-service programs aided in the preparation of future teachers to incorporate ICT in order to increase students' information literacy abilities. While the findings covered some areas, one important significant conclusion suggested that the pre-service teachers also perceived lack of training and time constraints as main barriers to developing students' information skills.

Teacher motivation and attitude towards technology are other main factors that influence the success of technology integration into the classroom. A study by 
Blackwell et al. (2016), who put emphasis on the importance of support provided by the school management, found that support provided by the school affects the traditional view and attitudes of the teachers. The study stressed the requirement for preschool teachers and teacher trainers to understand the critical contextual factors pertaining to technology use within the preschool setting and respond to such factors.

\subsection{Required Knowledge and Skills for Teachers}

Teachers, according to UNESCO, must have the knowledge and abilities to exploit new digital tools and resources to assist pupils attain high academic standards. Teachers must have fundamental ICT skills and competences in order for education to be of maximum advantage. Education must create new pedagogical models for ICT integration and learning, as well as techniques to improve the teaching-learning process within teacher education programs and ensure that all future instructors are well-prepared to use the new learning resources. Their primary role is to facilitate means for students to access technological applications for learning in a dynamic learning environment. Unlike the traditional learning environment where the teacher has more control than the student, teachers in technology-based learning environments-which are student-centered-need to have knowledge and skills on how to organize elearning programs to assist students in learning (Mahini et al., 2012).

Proper integration of ICT in education requires certain variables as defined by numerous studies. These variables are resources, rewards and incentives, the time factor, pedagogical factors, teacher attitudes, professional development, pedagogy, leadership, and attitudes of administrators. Consequently, the teachers' role is vital in the integration process because they need to have proper skills and knowledge to develop technology-rich learning experiences (Sang et al., 2010). Additionally, other authors identified the following competencies required by lecturers in ICT utilization in education: a) competence to make personal use of ICT in instruction; b) competence to master a range of educational paradigms that make use of ICT in instruction; c) sufficient competence to make use of ICTs as mind tools; d) competence to make use of ICT in instruction as a tool for teaching; e) competence in mastering a range of assessment paradigms which make use of ICT in instruction; and f) competence in understanding the policy dimensions of ICT use. Moreover, it can be underscored that a teaching competency matrix includes five competency areas needed for teachers to successfully integrate technology into their teaching. The five competency categories are: 1) community and netiquette; 2) active teaching/facilitating; 3) instructional design; 4) tools and technology; and 5) leadership and instruction.

It is important to note that ICT is never a substitute for good teaching. Without capable instructors, no electronic delivery can accomplish good results. However, neither traditional classroom teaching nor ICT driven classrooms can be successful if the teacher does not have the necessary skills. Nonetheless, ICT may be utilized in education to provide teaching and learning materials to teachers and students, increase teachers' and students' ICT abilities, provide 
teachers and students with access to information sources from across the world, and exchange ideas on education and learning. Furthermore, by working together on cooperative initiatives, ICT can deliver courses from a remote place while improving administrative efficiency.

\subsection{Integrating Technology into Teacher Professional Development}

Since the rise of technology in the 80 s, there have been extensive improvements by schools and educators to create strategies to use technology for the advancement of learning and teaching. These have not generally been converted into practical implementation, which has brought more attention to developing pre-service teachers' education programs before these students join the teaching profession. Technology must be integrated into teacher training to develop and maintain ICT capabilities to prevent the capabilities and competencies from becoming underutilized or isolated. Tondeur and colleagues (2016) pointed out that it is a truly difficult task for teacher training institutions to assist pre-service teachers in developing an ICT-based lesson and providing the necessary aid for them.

Teacher Training Institutes (TTIs) such as universities in the United Arab Emirates (UAE) and the world have incorporated technology into teacher training modules to give pre-service teachers an understanding of not just the usage of but also the pedagogical significance of technology usage in the 21stcentury teaching environment. Technology offers an efficient medium for communication and hence it can be used to accentuate teachers' pedagogical knowledge. Furthermore, the constant developments in technology make it imperative for in-service and pre-service teachers to continue learning about new technological tools, its capabilities, and applications in learning and teaching (Haines, 2016). Thus, it is very important to train teachers, not just in the use and application of technology, but also to constantly upgrade their capabilities to keep abreast of the latest developments in technology that can be applied in teaching. Furthermore, teachers are ongoing learners of ICT. As a result of accepting and adjusting ICT as an essential component of their employment, professionals will increase their ICT comprehension, leading to pedagogical benefits. Therefore, it is vital to offer teachers' training and professional development on both the technical and pedagogical aspects of ICT use across the curriculum.

In this respect, a Dutch study emphasized on the reasoning provided by the teachers concerning the application of technology in teaching (Heitink et al., 2016). The results highlighted that most of the technological use was directed to enhance and improve either pedagogy and subject matter or just pedagogy singly. Reasons addressed transformed learning into a more attractive activity, achieving goals of education and assisting the process of learning. Technology tools were utilized to assist an educational activity; technology was only required in a handful of the video cases. Nearly, half of the cases showed an adequate association between the reasoning offered and practice. The results assisted in obtaining a clearer picture of the professional reasoning offered by teachers to justify their use of technology. The study showed how teachers were 
developing their understanding and purposes of the use of technology over time. However, the focus should be on understanding the practical implementation of the different concepts of TPACK and its interaction, and how to implement the technology in the classrooms.

In a study conducted by Hargis et al. (2014) about faculty perceptions of iPad deployment in Higher Colleges of Technology in UAE, it was noted that the use of technology had a positive impact on faculty engagement, unofficial professional development activities, and adoption of dynamic student-centred pedagogy. The study indicated the following: 1) students' engagement increased as they were empowered and became more independent; 2) assignments' submission deadlines were met more often; 3) teachers' role was transformed into a facilitator rather than a lecturer; 4) peer coaching among faculty has been increased; 5) instructors started catering to different learning styles; 6) students and teachers started generating better quality material and deliverables by using applications; 7) courses then became more accessible due to the videos and materials posted in the iPad; and finally 8) students and teachers got more involved and enthusiastic with the new experience (Hargis et al., 2013).

\section{Conclusion}

Educators need to have adequate knowledge of the theoretical models of technology integration. Koehler and Mishra (2009) believed that some technologies have bias that makes it more applicable in some situations than others. Hence, understanding the theoretical models of integration of interactive learning technologies opens up lines of inquiry and suggestions for education policy development. It is imperative to implement funding models over and above the basic technology access to incorporate continuous educator support by establishing new modalities that strengthen professional development built upon learning-centred practices that the educators are motivated to use. Moreover, understanding the impact of technology integration on students learning capabilities is a way forward to better developing courses, subjects, and activities to foster quality attainment, as it goes beyond students' efforts, since teachers play a big role in achieving this objective.

\section{Limitations}

Every study has limitations, and the main limitation of the paper is the small number of models studied. Other models are worth covering and analysing.

\section{Recommendations}

A systematic review and meta-analysis should be conducted so that there would be a paper that contributes to the body of knowledge in this area. In addition, with the current COVID-19 situation, it is suggested to review studies that used these models and identify the context and outcome. Also, it would be interesting to see any new models emerging as a model of choice after the pandemic.

\section{Funding}

This study did not receive any specific grant from funding agencies in the public, commercial, or not-for-profit sectors. 


\section{References}

Ajzen, I. (1980). Understanding attitudes and predicting social behavior. New Jersey: Englewood Cliffs. https://ci.nii.ac.jp/naid/10011527857/

Ajzen, I., \& Driver, B. L. (1992). Application of the theory of planned behavior to leisure choice. Journal of Leisure Research, 24(3), 207-224. https:// doi.org/10.1080/00222216.1992.11969889

Angelo, S. M. (2017). Educators' perceptions of the substitution, augmentation, modification, redefinition model for technology integration. Northern Colorado: ProQuest LLC. https://search.proquest.com/openview/20acff786525cebe77a7c0b1c61aa2ce/1? pq-origsite $=$ gscholar\&cbl $=18750$

Avci, Z. Y., O'Dwyer, L. M., \& Lawson, J. (2020). Designing effective professional development for technology integration in schools. Journal of Computer Assisted Learning, 36(2), 160-177. https://doi.org/10.1111/jcal.12394

Blackwell, C. K., Lauricella, A. R., \& Wartella, E. (2016). The influence of TPACK contextual factors on early childhood educators' tablet computer use. Computers \& Education, 98, 57-69. https://doi.org/10.1016/j.compedu.2016.02.010

Brown, J. P. (2017). Teachers' perspectives of changes in their practice during a technology in mathematics education research project. Teaching and Teacher Education, 64, 52-65. https:// doi.org/10.1016/j.tate.2017.01.022

Castéra, J., Marre, C. C., Yok, M. C., Sherab, K., Impedovo, M. A., Sarapuu, T., Pedregosa, A. D., Malik, S. K., \& Armand, H. (2020). Self-reported TPACK of teacher educators across six countries in Asia and Europe. Education and Information Technologies, 25(4), 3003-3019. https://doi.org/10.1007/s10639-02010106-6

Chandler, D., \& Munday, R. (2020). A dictionary of media and communication. https://doi.org/10.1093/acref/9780198841838.001.0001

Cheng, S., Lu, L., Xie, K., \& Vongkulluksn, V. W. (2020). Understanding teacher technology integration from expectancy-value perspectives. Teaching and Teacher Education, 91, 103062. https://doi.org/10.1016/j.tate.2020.103062

Chou, C. C., Block, L., \& Jesness, R. (2012). A case study of mobile learning pilot project in K-12 schools. Journal of Educational Technology Development and Exchange, 5(2). https://doi.org/10.18785/jetde.0502.02

Davis, F. D. (1989). Perceived usefulness, perceived ease of use, and user acceptance of $\begin{array}{llll}\text { information technology. MIS Quarterly, 13(3), } 319 . & \end{array}$ https://doi.org/10.2307/249008

Ellis, J., Dare, E., \& Roehrig, G. (2016). From consumers to creators: Adventures learning and its impact on pre-service teachers' TPACK and technology integration. Society for Information Technology \& Teacher Education International Conference, 28342841.

Goh, E., \& Wen, J. (2020). Applying the technology acceptance model to understand hospitality management students' intentions to use electronic discussion boards as a learning tool. Journal of Teaching in Travel \& Tourism, 21(2), 142-154. https://doi.org/10.1080/15313220.2020.1768621

Gong, M., Xu, Y., \& Yu, Y. (2004). An enhanced technology acceptance model for webbased learning. Journal of Information Systems Education, 15(4), 365-374. https://jise.org/volume15/n4/JISEv15n4p365.html

Haines, K. (2016). Expanding the knowledge base of teachers' use of communication tools for language learning. System, 62, 102-112. https://doi.org/10.1016/j.system.2016.07.008 
Hao, Y., \& Lee, K. S. (2016). Teaching in flipped classrooms: Exploring pre-service teachers' concerns. Computers in Human Behavior, 57, 250-260. https://doi.org/10.1016/j.chb.2015.12.022

Hardman, J. (2019). Towards a pedagogical model of teaching with ICTs for mathematics attainment in primary school: A review of studies 2008-2018. Heliyon, 5(5), e01726. https://doi.org/10.1016/j.heliyon.2019.e01726

Hargis, J., Cavanaugh, C., Kamali, T., \& Soto, M. (2014). A federal higher education iPad mobile learning initiative: Triangulation of data to determine early effectiveness. Innovative Higher Education, 39(1), 45-57. https://doi.org/10.1007/s10755-0139259-y

Harris, J., \& Hoffer, M. J. (2014). The construct is in the eye of the beholder: School districts'. SITE 2014-Society for Information Technology \& Teacher Education International Conference., 2519-2526.

Harrison, C., Comber, C., Fisher, T., Haw, K., Lewin, C., \&Lunzer, E. (2002). The impact of information and communication technologies on pupil learning and attainment. British Educational Communications and Technology Agency (BECTA). https://scholar.google.com/citations?view_op=view_citation\&hl=en\&user=utQP28AAAAJ\&citation_for_view=ut-QP28AAAAJ:u5HHmVD_uO8C

Heitink, M., Voogt, J., Verplanken, L., Van Braak, J., \& Fisser, P. (2016). Teachers' professional reasoning about their pedagogical use of technology. Computers $\mathcal{E}$ Education, 101, 70-83. https:// doi.org/10.1016/j.compedu.2016.05.009

Hood, M., Creed, P. A., \& Neumann, D. L. (2012). Using the expectancy value model of motivation to understand the relationship between student attitudes and achievement in statistics. Statistics Education Research Journal, 11(2), 72-85. https://doi.org/10.52041/serj.v11i2.330

Johnston, K., Hadley, F., \& Waniganayake, M. (2019). Practitioner inquiry as a professional learning strategy to support technology integration in early learning centres: Building understanding through Rogoff's planes of analysis. Professional Development in Education, 46(1), 49-64. https://doi.org/10.1080/19415257.2019.1647871

Koehler, M., \& Mishra, P. (2009). What is technological pedagogical content knowledge (TPACK)? Contemporary Issues in Technological and Teacher Education, 9(1), 60-70. https://www.learntechlib.org/p/29544/

Koh, J. H., Chai, C. S., \& Lee, M. (2015). Technological pedagogical content knowledge (TPACK) for pedagogical improvement: Editorial for special issue on TPACK. The Asia-Pacific Education Researcher, 24(3), 459-462. https:// doi.org/10.1007/s40299-015-0241-6

Mahini, F., Forushan, Z. J., \& Haghani, F. (2012). The importance of teacher's role in technology-based education. Procedia - Social and Behavioral Sciences, 46, 16141618. https://doi.org/10.1016/j.sbspro.2012.05.348

Miguel-Revilla, D., Martínez-Ferreira, J. M., \& Sánchez-Agustí, M. (2020). Assessing the digital competence of educators in social studies: An analysis in initial teacher training using the TPACK-21 model. Australasian Journal of Educational Technology. https://doi.org/10.14742/ajet.5281

Mishra, P., \& Koehler, M. J. (2006). Technological pedagogical content knowledge: A framework for teacher knowledge. Teachers College Record, 108(6), 1017-1054. https://doi.org/10.1111/j.1467-9620.2006.00684.x

Pavlou, V. (2019). Art technology integration: Digital Story tellying as a transformative pedagogy in primary education. International Journal of Art \& Design Education, 39(1), 195-210. https://doi.org/10.1111/jade.12254 
Peterson, P. L., \& Clark, C. M. (1978). Teachers' reports of their cognitive processes during teaching. American Educational Research Journal, 15(4), 555-565. https:// doi.org/10.3102/00028312015004555

Sang, G., Valcke, M., Braak, J. V., \& Tondeur, J. (2010). Student teachers' thinking processes and ICT integration: Predictors of prospective teaching behaviors with educational technology. Computers \& Education, 54(1), 103-112. https://doi.org/10.1016/j.compedu.2009.07.010

Shulman, L. S. (2013). Those who understand: Knowledge growth in teaching. Journal of Education, 193(3), 1-11. https://doi.org/10.1177/002205741319300302

Stockwell, G., \& Liu, Y. C. (2015). Engaging in mobile phone-based activities for learning vocabulary: An investigation in Japan and Taiwan. CALICO Journal, 32(2), 299322. https://doi.org/10.1558/cj.v32i2.25000

Sukendro, S., Habibi, A., Khaeruddin, K., Indrayana, B., Syahruddin, S., Makadada, F. A., \& Hakim, H. (2020). Using an extended technology acceptance model to understand students' use of e-learning during COVID-19: Indonesian sport science education context. Heliyon, 6(11), e05410. https://doi.org/10.1016/j.heliyon.2020.e05410

Tamilmani, K., Rana, N. P., Wamba, S. F., \& Dwivedi, R. (2021). The extended unified theory of acceptance and use of technology (UTAUT2): A systematic literature review and theory evaluation. International Journal of Information Management, 57, 102269. https://doi.org/10.1016/j.ijinfomgt.2020.102269

Tamim, R. M., Bernard, R. M., Borokhovski, E., Abrami, P. C., \& Schmid, R. F. (2011). What forty years of research says about the impact of technology on learning: A second-order meta-analysis and validation study. Review of Educational Research, 81(1), 4-28. https://doi.org/10.3102/0034654310393361

Terada, Y. (2020). A powerful model for understanding good tech integration. https://www.collegeforbishops.org/s/SAMR_-A-Powerful-Model-forUnderstanding-Good-Tech-Integration-_-Edutopia.pdf

Tondeur, J., Scherer, R., Siddiq, F., \& Baran, E. (2019). Enhancing pre-service teachers' technological pedagogical content knowledge (TPACK): A mixed-method study. Educational Technology Research and Development, 68(1), 319-343. https://doi.org/10.1007/s11423-019-09692-1

Tondeur, J., van Braak, J., Sang, G., Voogt, J., Fisser, P., \& Ottenbreit-Leftwich, A. (2012). Preparing pre-service teachers to integrate technology in education: A synthesis of qualitative evidence. Computers $\mathcal{E}$ Education, 59(1), 134-144. https:// doi.org/10.1016/j.compedu.2011.10.009

Tondeur, J., Van Braak, J., Siddiq, F., \& Scherer, R. (2016). Time for a new approach to prepare future teachers for educational technology use: Its meaning and measurement. Computers $\mathcal{E}$ Education, 94, 134-150. https://doi.org/10.1016/j.compedu.2015.11.009

United Arab Emirates. (n.d.). Sustainable development knowledge platform. https://sustainabledevelopment.un.org/memberstates/unitedarabemirates

Vanduhe, V. Z., Nat, M., \& Hasan, H. F. (2020). Continuance intentions to use gamification for training in higher education: Integrating the technology acceptance model (TAM), social motivation, and task technology fit (TTF). IEEE Access, 8, 21473-21484. https://doi.org/10.1109/access.2020.2966179

Venkatesh, V., Morris, M.G., Davis, G.B., \& Davis, F.D. (2003). User acceptance of information technology: Toward a unified view. MIS Quarterly, 27(3), 425-478. https://doi.org/10.2307/30036540 
Wigfield, A., \& Eccles, J. S. (2000). Expectancy-value theory of achievement motivation. Contemporary Educational Psychology, 25(1), 68-81. https://doi.org/10.1006/ceps.1999.1015

Woo, H., Dondanville, A., Jang, H., Na, G., \& Jang, Y. (2020). A content analysis of the counseling literature on technology integration: American Counseling Association (ACA) counseling journals between 2000 and 2018. International Journal for the Advancement of Counselling, 42(3), 319-333. https:// doi.org/10.1007/s10447-020-09406-w

Yeh, Y., Hsu, Y., Wu, H., \& Chien, S. (2017). Exploring the structure of TPACK with video-embedded and discipline-focused assessments. Computers \& Education, 104, 49-64. https://doi.org/10.1016/j.compedu.2016.10.006

Young, J. R., Young, J. L., \& Hamilton, C. (2013). The use of confidence intervals as a meta-analytic lens to summarize the effects of teacher education technology courses on preservice teacher TPACK. Journal of Research on Technology in Education, 46(2), 149-172. https://doi.org/10.1080/15391523.2013.10782617 